\title{
Innovation in groups: does the proximity of others facilitate or inhibit performance?
}

\author{
Sarah E. Overington ${ }^{1,3)}$, Laure Cauchard ${ }^{1)}$, Julie Morand-Ferron ${ }^{2)} \&$ \\ Louis Lefebvre ${ }^{1)}$ \\ ( ${ }^{1}$ Department of Biology, McGill University, 1205 Ave Dr Penfield, Montréal, Québec, \\ Canada H3A 1B1; ${ }^{2}$ Département des Sciences Biologiques, Université du Québec à \\ Montréal, C.P. 8888 Succursale Centre-Ville, Montréal, Québec, Canada H3P 3P8)
}

(Accepted: 1 May 2009)

\begin{abstract}
Summary
Foraging innovation, in which an individual eats a novel food or uses a novel foraging technique, has been observed in a wide range of species. If other individuals are nearby, they may adopt the innovation, thus spreading it through the population. Much research has focused on this social transmission of behaviour, but the effect of social context on the emergence of novel behaviour is unclear. Here, we examine the effect of social context on innovative feeding behaviour in the Carib grackle (Quiscalus lugubris), an opportunistic, gregarious bird. We test the effect of the proximity of conspecifics, while eliminating the direct effects of interference, scrounging, or aggression. Using a repeated-measures design, we found that birds took significantly longer to contact novel foraging tasks when in the presence of others vs. alone, and during playbacks of alarm calls vs. a control sound. Further, performance of a food-processing behaviour decreased when birds were with others, and individuals adjusted their behaviour depending on their distance from conspecifics. Our results suggest that feeding in groups may slow down or inhibit innovative foraging behaviour in this species. We discuss the implications of a trade-off between feeding in groups and taking advantage of new feeding opportunities.
\end{abstract}

Keywords: social foraging, Quiscalus lugubris, innovation, problem-solving, neophobia, dunking.

3) Corresponding author's e-mail address: sarah.overington@mcgill.ca 


\section{Introduction}

Foraging innovations have been observed in over 800 species of birds in the wild, and may range from simply eating a new type of food (Sibson, 1993) to novel foraging techniques such as using tools (Gayou, 1982). These novel behaviours can allow animals to take advantage of new food sources and habitats. Once an individual has innovated, the novel behaviour can spread socially and become part of the behavioural repertoire of whole populations (Reader \& Laland, 2000; Lefebvre \& Bouchard, 2003; Boogert et al., 2008), allowing shifts to new adaptive zones and influencing evolutionary rates through behavioural drive (Nicolakakis et al., 2003; Sol et al., 2005).

Despite the potential importance of innovativeness in ecology and evolution, little is known about when or how innovation occurs (Reader \& Laland, 2003; Clayton, 2004). Comparative studies show that innovativeness is positively correlated with residual size of the brain in both birds and primates (Lefebvre et al., 1997b; Reader \& Laland, 2002), which suggests that cognitive capacity can facilitate (or limit) the ability of a species to innovate. Group living is also positively correlated with enlarged brain size (Byrne \& Whiten, 1988; Dunbar, 1998), and a recent study of 480 species of birds demonstrated that the largest brains are found in species that live in pairs or in groups of up to 70 individuals (Emery et al., 2007). Together, these comparative studies raise the question of how ecological and social pressures interact to shape cognition (Shultz \& Dunbar, 2006; Overington et al., 2008). If large-brained species are both innovative and social, the social environment could play an important role in the emergence of novel behaviour patterns. Although comparative work in this area raises interesting questions, this approach cannot examine the relationship between innovation and sociality at the individual level.

In this study, we use an experimental approach to test how social context influences two types of foraging innovations in the Carib grackle (Quiscalus lugubris). First, we present birds with an innovation task that requires them to remove an obstacle to reach food, a test that has been used to understand innovation in a variety of bird species (Webster \& Lefebvre, 2001; Huber \& Gajdon, 2006; Bouchard et al., 2007; Biondi et al., 2008; Boogert et al., 2008). Second, we examine a behaviour that was recently reported as an innovation in our study species, the processing of hard dry food by dunking 
it in water (Morand-Ferron et al., 2004, 2006, 2007). Although observed at very low frequency in the field, dunking can become part of the standard behavioural repertoire of grackles; over $80 \%$ of individuals will dunk dry, hard food in captivity (Morand-Ferron et al., 2004). As a behaviour exhibited spontaneously by wild grackles, dunking provides an ecologically-relevant addition to the standard innovation tasks to test how social context influences the expression of innovative foraging techniques. We test the effects of social context on these two behaviours by manipulating presence of grackles near a focal individual, and by broadcasting a conspecific alarm chorus or a control sound during testing.

Previous studies suggest that there are both costs and benefits to group feeding. Carib grackles use social information to learn new feeding techniques (Lefebvre et al., 1997a) and to identify predators (Griffin \& Galef, 2005). In some species, the presence of others can increase exploration (capuchin monkeys: Fragaszy \& Visalberghi, 1990), decrease neophobia (zebra finches: Coleman \& Mellgren, 1994), and reduce anti-predator vigilance (for a review, see Lima \& Dill, 1990), all of which should facilitate innovation.

On the other hand, group-feeding may be costly. Carib grackles incur direct costs when feeding in groups because they steal food from one another (Morand-Ferron et al., 2006, 2007). Contrary to the findings described above for zebra finches, group feeding sometimes increases neophobia (common ravens: Stöwe et al., 2006), and the presence of uninformed conspecifics in a group can slow down social learning (the 'bystander effect' in pigeons: Lefebvre \& Giraldeau, 1994), raising the possibility that the presence of others could slow or inhibit innovation.

If innovating grackles benefit from the presence of others, the latency to solve the innovation task should be lower when other grackles are nearby and higher when a conspecific alarm chorus is broadcast. We would also predict a higher rate of dunking. If, on the contrary, the presence of conspecifics has a negative effect on innovating grackles, we should expect a higher latency to solve the innovation task and a lower rate of dunking. We also predict that grackles will adjust their dunking behaviour to avoid potential theft, by moving further away from conspecifics or using a hide when dunking food items, similar to the anti-theft strategies observed in corvids (Clayton et al., 2007), and in parids (Pravosudov, 2008). 


\section{General methods}

Study species

On the very anthropogenically-modified West Indian island of Barbados, Carib grackles routinely feed in small, open flocks on food directly related to human activities (Jaramillo \& Burke, 1999), and regularly encounter novel food items. Comparative work also suggests that they are a good species for studies of innovation: an exhaustive survey of reports of innovative behaviour in ornithology journals show that Quiscalus is the passerine genus with the second highest number of reports after Corvus, which includes crows and ravens (Lefebvre et al., 1997b; Webster \& Lefebvre, 2001).

\section{Subjects and housing}

We caught 58 adult Carib grackles from February to May 2006 and February to June 2007 in baited, walk-in traps on the grounds of the Bellairs Research Institute of McGill University, St. James, Barbados. None of these birds had participated in any previous behavioural experiments. Upon capture, we weighed and measured each individual, fitted them with a unique combination of coloured aluminium bands (A.C. Hughes, UK), and housed them in individual cages $(2.25 \times 2.15 \times 0.76 \mathrm{~m})$ in an outdoor aviary. Sexes were assigned visually based on plumage, size and behavioural observations in consultation with a local ornithologist (Martin Frost, pers. commun.). DNA testing of blood samples of individuals caught at our site (Griffiths et al., 1998 ) in the context of an ongoing morphological study confirmed that we were able to assign sexes to adult birds with 95\% accuracy, and that we were able to identify large adult male birds such as those used in our 2007 experiments with $100 \%$ accuracy. Aviary cages were separated from each other by opaque plastic sheets, so that subjects were visually, but not acoustically, isolated. Water was available ad libitum throughout the experimental period. Food (soaked, crushed dog food pellets, and cooked rice) was provided ad libitum for the first two days in captivity, and after trials on test days. Food was removed at $1800 \mathrm{~h}$ every evening, and birds were food-deprived until experiments began between 0800 and $0900 \mathrm{~h}$ the following morning. All birds were released near their site of capture when they had completed the experiments. No birds were re-used in experiments after release. Time in captivity ranged from 10 to 14 days. All experiments were conducted according to Animal Use Protocol 5123, approved by the McGill University Animal Care Committee. 


\section{Experiment 1: Do conspecific alarm calls influence innovative problem-solving?}

\section{Subjects}

Experiment 1 was carried out from February to May, 2006. Fifteen adult birds (11 males, 3 females and 1 unidentified at the time of study but likely female, based on morphology; Overington, unpublished data) served as subjects for this experiment. Prior to the experiment, all birds had participated in an experiment in which they had interacted with another problem-solving task (task A; Figure 1).

\section{Experimental protocol}

We began experimental manipulations from day 8 to day 13 in captivity. In this experiment, we presented individuals with novel problem-solving tasks during playback of either conspecific alarm calls or a neutral sound. The conspecific alarm call chorus was recorded at Bellairs Research Institute by Andrea S. Griffin, who used the playbacks in several experiments on social learning about predators (Griffin \& Galef, 2005; Griffin et al., 2005) and kindly provided us with the audio files. In the wild, these alarm calls are made in the presence of cats, mongooses, monkeys, and dogs (Griffin

$\mathbf{A}$

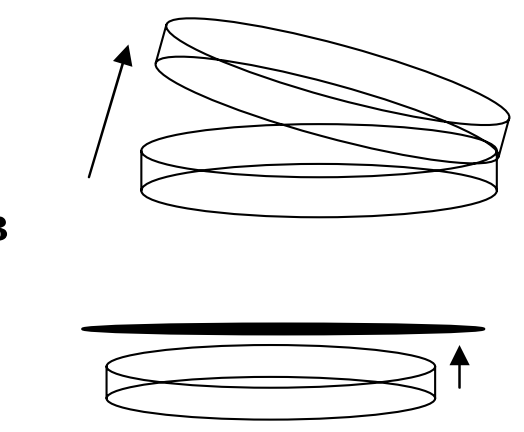

B
C

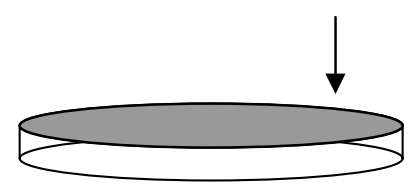

D

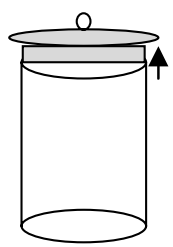

Figure 1. The innovation tasks: in experiment 1, birds removed a black foam lid from task (B) or pecked through the aluminum foil lid of task (C). In experiment 2, birds opened the lid of hinged task (A), or removed the cap, either by holding the handle or flipping the lid with their bills, of task (D). 
\& Galef, 2005). The alarm call chorus used in this experiment was elicited by presenting several individuals with a stuffed cat, and the recordings were edited so that one series of alarm calls was played through the left speaker and another through the right, to simulate several birds calling from different locations. The neutral sound was designed to control for the sudden, loud sound being played into the cage. It was recorded for this experiment with an Audio-Technica AT815b directional microphone into a Gateway computer. The recording consisted of ambient background noise (waves and people walking on the beach) as well as the songs of grackles and bananaquits ( $\mathrm{Co}$ ereba flaveola). Each recording (alarm call/neutral) was cut into a 120-s clip that was played during experiments through two Harman Kardon speakers attached to a Gateway computer. The recordings were played at a maximum amplitude of $90 \mathrm{~dB}$ when measured in the cage one m away from the speakers. Recordings are available from the authors upon request.

For each trial (call/control), we first presented the bird with a hinged fooddish (task A) which they had learned to open in a previous experiment to ensure a baseline level of motivation. The experiment only proceeded if the bird opened task A within 5 min. The experimenter then removed the task through a small door at the front of the cage. Sixty seconds later, sound playbacks began through speakers in front of the cage. We placed one of two novel tasks (either task B or C; Figure 1) in the cage $10 \mathrm{~s}$ after the start of the playback. Playbacks occurred during the first two minutes of each trial. The task was removed from the cage $10 \mathrm{~s}$ after the bird successfully solved the task, or after a maximum of $20 \mathrm{~min}$. Order of trials (call/control) was assigned by coin toss, and the task presented with each sound was chosen using a balanced design across birds. We conducted trials between 0800 and $1000 \mathrm{~h}$, and at the same time on each of two successive days for each bird. Tasks B and C looked similar; both had opaque lids covering transparent, Petri-dish bases, and were attached to wooden feeding platforms, and both were baited with a mix of cooked rice and crushed dog food pellets. However, they required different opening techniques. For task B, a black foam lid had to be lifted to reach the food (Figure 1). To open task C, birds had to puncture the aluminium foil of the lid (Figure 1).

All data were log-transformed, and paired $t$-tests were used to compare innovation measures during playback of the conspecific alarm chorus versus the control sound. 


\section{Results}

We used a repeated-measures design to account for the individual differences among subjects. There were no systematic differences between male $(N=$ $11)$ and female $(N=4)$ birds for any of our measures, and we report all results with the full dataset $(N=15)$. Playbacks occurred during the first 2 min of each trial. Only 2 out of 15 birds contacted the tasks during the 2 min of alarm call playbacks, whereas eight birds contacted tasks during the two minutes of control sound playback $\left(\chi^{2}=3.8, p=0.05\right)$. However, all individuals in this experiment eventually contacted each task during each 20 minute trial. Birds took longer in call trials than in control trials to descend to the ground (mean time \pm SE to drop from perch: $132 \pm 32 \mathrm{~s} \mathrm{vs.} 50 \pm 13 \mathrm{~s}$; $t_{14}=-2.2, p=0.04$ ). Birds also took longer to contact the tasks (mean latencies \pm SE: $258 \pm 55 \mathrm{~s}$ vs. $136 \pm 55 \mathrm{~s} ; t_{14}=-2.9, p=0.01 ; t_{14}=-2.6$, $p=0.02$; Figure 2a) in call trials than in control trials. However, problem-
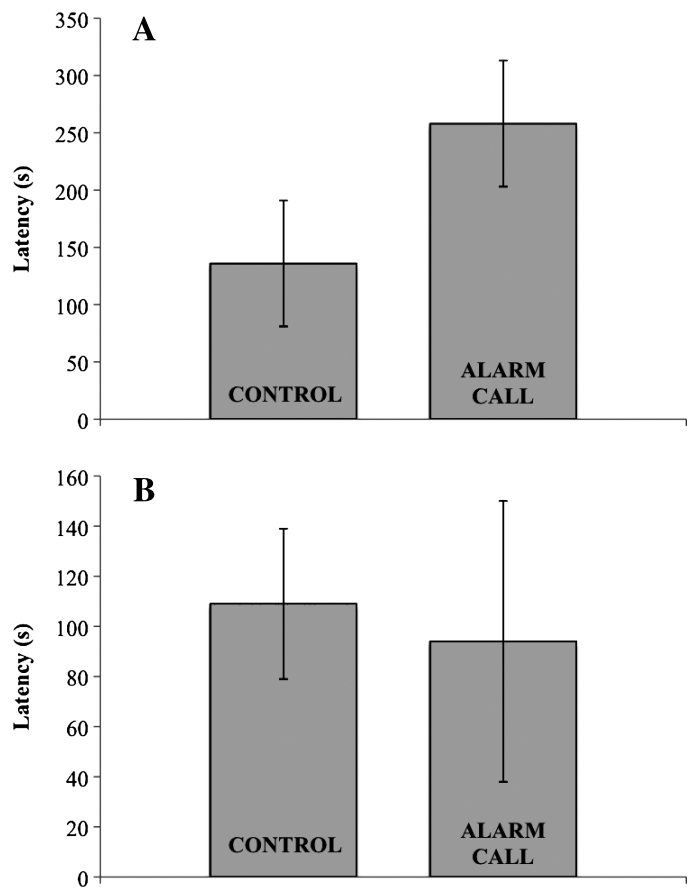

Figure 2. Experiment 1: group means of (A) time to contact the tasks and (B) problemsolving efficiency (the time to open the task after first contact) during playback of alarm calls and control sound $(N=15)$. Note that means of raw data $\pm \mathrm{SE}$ are shown here; paired $t$-tests were carried out on log-transformed data. 
solving efficiency, measured as the time between contact and solving, was not significantly different between trials (mean time \pm SE: $109 \pm 30 \mathrm{~s}$ vs. $94 \pm 56 \mathrm{~s} ; t_{14}=-1.24, p=0.25$; Figure $2 \mathrm{~b}$ ).

\section{Experiment 2: Does social context influence innovative problem-solving?}

\section{Subjects}

Experiment 2 was carried out between February and May 2007. Forty-five adult male birds served as subjects in these experiments, and none of these individuals had participated in Experiment 1 in 2006. Because we could keep a maximum of 12 birds in the aviary at any one time, we caught birds in five sets, each made up of 5-11 birds. Subjects were kept in individual cages in an outdoor aviary, whereas the last two birds per set were housed in one cage together to form the 'social group' for these experiments, and were never used as subjects themselves. Overnight food deprivation began on the third day in captivity.

\section{Experimental protocol: control trials}

On day six in captivity, we began the first problem-solving trials. We presented individuals with a novel foraging task, a transparent hinged dish (task A; Figure 1). The food reward (soaked and crushed dog food) was placed in the centre of the dish. Individuals had to open the dish to reach the reward. Once the individual had reached the food, they were considered to have solved the task. We recorded the latency to contact and to solve the task. Task presentations lasted up to $5 \mathrm{~min}$, and were separated by at least $30 \mathrm{~min}$. Birds were given up to 5 attempts on the morning of day 6 (trials 1-5), 6 attempts on the morning of day 7 (trials 6-11) and 5 attempts in the afternoon of day 7 (trials 12-16). Twenty-nine birds solved the task in trials $1-9,1$ individual solved the task between trials 10 and 16 , and 5 individuals never solved the task. Performance on this innovation task served as a baseline measure, and we compared individual performance on this task with performance in one of two test conditions (see Figure 3 for a schematic of experimental design). 


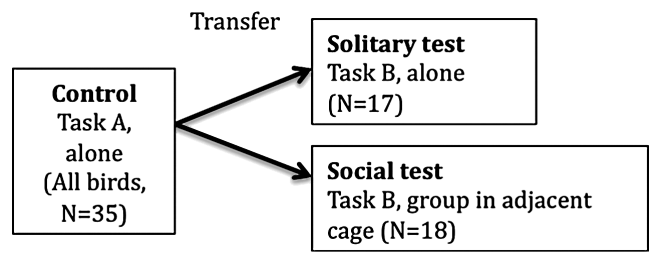

Figure 3. Design of experiment 1. Each individual was given task A in the control condition. Individuals were then either transferred to the solitary or social test condition. Performance on task B in the test condition was then compared to performance on task A in the control.

\section{Transfer to experimental condition}

On the morning of the 8th to 13th day in captivity, we moved birds to the test condition (another cage the same size as their initial cage, $2.25 \times 2.15 \times$ $0.76 \mathrm{~m})$ in a small transfer cage $(37 \times 30 \times 31 \mathrm{~cm})$ baited with food. We did not directly handle birds during the transfer. We assigned transfer day based on cage availability for social birds, whereas we assigned transfer days to solitary birds randomly, so that transfer days would be equally variable within both groups. We randomly assigned subjects to either the solitary ( $N=18)$ or social $(N=17)$ treatment. We transferred birds assigned to the solitary condition to a new cage that was visually isolated from other birds. In the social condition, birds were transferred to a cage adjacent to the 'group cage' which housed two other birds. The target subject's cage was separated from the group cage by one layer of metal grid, and the set-up within the test cage was the same as in control trials. This separation allowed us to assess the effects of social context on performance while preventing social birds from opening the apparatus in lieu of the tested individual, which would have yielded a trivial answer on the effect of social vs. non-social context on problem-solving performance. This decision should not affect the type 1 error, as it presumably represents a weaker social situation than having all birds in the same cage, though a lack of effect could be attributable to a type 2 error. All birds were given ad libitum access to food after transfer to their testing or conspecific cages, then food-deprived overnight.

\section{Experimental protocol: test trials}

Problem-solving trials began in the morning of the day after transfer to the new condition. We presented birds with a new problem-solving task 
(task D; Figure 1) up to 11 times while in the experimental condition (social or solitary). Again, trials were $5 \mathrm{~min}$ long, or until the bird opened the task successfully. Trials were separated by at least $30 \mathrm{~min}$. We recorded the time when birds contacted the task and successfully solved the task. Because there was a great deal of variation between individual performances on all tests, we used repeated-measures analyses, and compared the performance of birds in control versus treatment conditions, where the treatment conditions were solitary or social. Our data from the innovation tasks were not normally distributed even after transformation. We, therefore, used nonparametric tests on our raw data. We carried out separate Wilcoxon paired tests on birds transferred to the social and solitary conditions.

\section{Calling rates during experiments}

In experiment 1 , playback of alarm calls slowed down innovation. In captivity, Carib grackles often broadcast a low-rate, low-volume version of the alarm call chorus (see Griffin \& Galef, 2005). To verify that an eventual inhibitory effect of the social group in experiment 2 was not confounded by such calling, we quantified the rate of 'chuck' calls heard in the aviary during the first test trial for 17 birds (9 solitary, 8 social), including at least one bird in each condition for each of our five test groups of birds. For the solitary condition, the calls could come from the grackles caged out of sight a few meters away in the aviary; for the social condition, they could come from the same aviary neighbours or from the conspecifics in the adjacent cage. We estimated calling rate by counting the total number of chucks from video recorded trials using Jwatcher (Blumstein et al., 2000). We also counted the number of chucks per minute in the alarm call playback used in experiment 1 using Jwatcher.

\section{Results}

Of the 36 birds in our experiment, 26 solved both innovation tasks. For the 10 birds that did not solve the tasks, we include the number of social (soc) and solitary (sol) birds in parentheses to show how the non-solvers were distributed over the two conditions. Three birds did not solve either of the two tasks ( 1 soc, 2 sol). Seven birds solved only one of the two tasks; 3 birds solved only task 1 ( 1 soc, 2 sol), and 4 birds solved only task 2 ( 2 soc, 2 sol). 

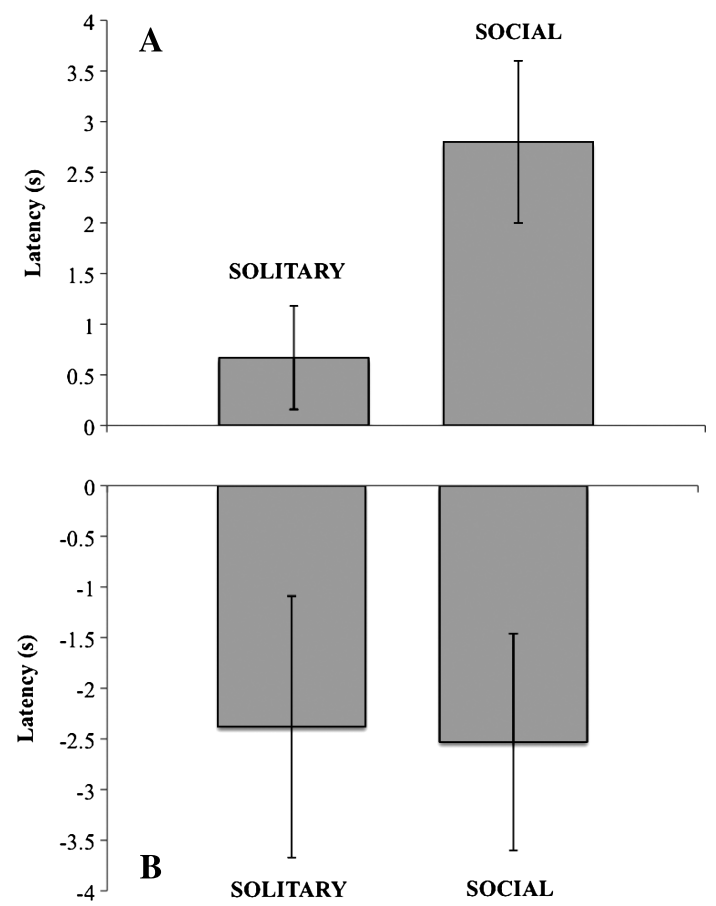

Figure 4. Experiment 2: group means of the difference in (A) trials to contact the task and (B) trials to open the task between control and test trials for birds transferred to the solitary $(N=18)$ and social $(N=17)$ test conditions. Birds transferred to the social condition showed a significant increase in the trials to contact the task, but all other differences were not significant. Nonparametric tests were carried out on raw data.

Birds in the social condition contacted the novel tasks in a later trial (Figure 4a; mean $\pm \mathrm{SE}$ change $=+2.8 \pm 0.8$ trials; $Z=-2.8, N=18$, $p=0.006$ ), and with a longer latency in that trial (mean \pm SE change $=$ $+50 \pm 34 \mathrm{~s} ; Z=-2.0, N=16, p=0.05)$ than they did in the controls. Birds in the solitary condition did not take any longer to contact the novel tasks (Figure 4a; mean $\pm \mathrm{SE}$ change $=+0.67 \pm 0.51$ trials: $Z=-1.2$, $N=18, p=0.23$; mean \pm SE change in latency $=-13.8 \pm 28$ s latency: $Z=-0.7, N=18, p=0.47$ ).

These analyses included all birds that contacted at least one task. We repeated our analyses excluding birds that did not solve either task, and there were no differences in our results. For analyses comparing the trial when birds solved, we excluded individuals that did not solve both tasks (as listed above). Social context did not have any effect on the trial when birds 
solved the task (Figure $4 \mathrm{~b}$; social: $Z=-1.5, N=14, p=0.13$; solitary: $Z=-0.9, N=12, p=0.34)$, the total time it took for them to solve the task (social: $Z=-0.9, N=14, p=0.35$; solitary: $Z=-1.8, N=12$, $p=0.07$ ), or in problem-solving efficiency (social: $Z=-1.6, N=14$, $p=0.10$; solitary: $Z=-1.5, N=12, p=0.14$ ).

The rate of chucking in our recorded alarm call chorus in experiment 1 was at least 236 chucks/min (the chucking rate was so high that it was difficult to count each chuck), which was far greater than the average of 35 chucks/min (range 7-81) during test trials in experiment 2. There was no difference in chuck rate heard from nearby caged grackles during solitary or social test trials $(U=51, N=17, p=0.15)$. Birds solved the innovation task during three of the 17 trials for which we quantified chuck rate. Chuck rate during these successful trials was not noticeably different from any of the non-successful trials (chuck rates of successful trials were 56, 31 and 44 chucks/min). It is, therefore, unlikely that the effects of the social condition of experiment 2 are due to calling per se.

\section{Experiment 3: Does social context influence dunking behaviour?}

\section{Subjects}

Experiment 3 was carried out in the afternoons following the problemsolving trials of experiment 2 . All 35 focal subjects and 10 group birds had previously participated in experiment 2 .

\section{Experimental protocol}

We carried out four dunking trials with each individual. Birds were fooddeprived in the middle of the day for 3.5 to $4 \mathrm{~h}$ before experimental trials began. Birds were never exposed to whole dry dog food pellets in captivity until the dunking trials began, though this is an item that captive grackles will spontaneously dunk (Morand-Ferron et al., 2004). On the fifth day in captivity, we replaced each bird's regular water dish with one concealed in a hide. The hide was a dark green box $(30 \times 31 \times 37 \mathrm{~cm})$, open at the front and at the top, with wooden sides and a metal floor. The bottom of a large Petri dish (diameter $10 \mathrm{~cm}$ ) was affixed inside the hide with duct tape. Birds readily drank from the water dish inside the hide, even when the 
other water dish was available, and often used the hide as an additional perch in the cage. We placed the regular water dish beside the hidden water dish before starting experiments. On the afternoon of the sixth and seventh day in captivity we carried out dunking trials 1 and 2, respectively. These were the control trials, and involved only birds held singly in individual cages. In each trial, we placed three dry dog pellets $15 \mathrm{~cm}$ from the front of the cage, equidistant from the two water dishes. Each dunking trial lasted $20 \mathrm{~min}$ after the placement of the dog pellets. The observer, watching through a small hole in a hide $2 \mathrm{~m}$ from the cage, recorded the following variables: time at which the bird first contacted the pellets, time at which it dunked the pellets, time at which the bird removed pellets from water, and the location of each dunk ('open' or 'hidden' water dish). We alternated the position of the two water dishes (i.e., on the left or right side of the cage door) for each dunking trial.

We carried out dunking trials 3 and 4 (test trials) after the birds were transferred to the test condition (social or solitary; for details of transfer, see experiment 2), following the same protocol as the control trials. For one of the test trials, the 'near' condition, the open dish was directly beside the group cage (approx. $10 \mathrm{~cm}$ from the division between the cages), while the hidden box was further away (approx. $40 \mathrm{~cm}$ from the group cage). In the other trial, the open dish was approx. $40 \mathrm{~cm}$ from the group cage, with the hidden water dish being placed $10 \mathrm{~cm}$ from the group cage, making the open dish 'far'. The order of the 'near' and 'far' trials was randomly determined. We fed group birds prior to the dunking trials to avoid overt aggression between them which occurred only when birds had been food-deprived. Food was then removed from the group five minutes before the start of the dunking trials.

Measures related to dunking (time to contact first food pellet, latency to first dunk, total number of dunks, time spent dunking and duration of the longest dunk) were normally distributed after log 10-transformations. As in the previous experiment, we analyzed the effects of social context by splitting our data into 'solitary' and 'social' groups. Because the control was the same for both groups but the experimental manipulation differed, we tested for differences between control and test conditions for each group using paired $t$-tests. For birds in the 'social' group, we further tested for any behavioural differences between 'near' and 'far' conditions. In this case, the same subjects were used in each treatment and we were able to use repeated-measures ANOVA to test whether behaviour was different between conditions. 


\section{Results}

We carried out a total of 140 dunking trials with the 35 birds in our experiment. Of these birds, three did not dunk in any of the four trials, and were, therefore, excluded from analyses.

Use of the hide when dunking

Birds dunked food in 115 (82\%) trials, and did not dunk in $25(18 \%)$ trials. Of the trials in which birds dunked, only $5(4 \%)$ involved any dunking in the hidden water dish. Five individuals each dunked in the hide in one of their four dunking trials; these birds had been assigned almost equally to the social $(N=2)$ and solitary $(N=3)$ conditions. Four of the five incidents of dunking in the hide occurred in dunking trials 1 and 2 (controls), whereas only one occurred during the test trials. However, this difference was not significant; subjects did not increase their use of the hidden dish in test trials (Wilcoxon paired test: solitary: $Z=-0.6, N=18, p=0.56$; social: $Z=-1.4, N=15, p=0.16$ ).

Social effects on dunking behaviour

Birds in both conditions took longer to contact food pellets in test trials than they did in their original cages (paired $t$-tests: solitary: $t_{17}=-3.0$, $p=0.008$; social: $\left.t_{14}=-3.8, p=0.002\right)$. Neither condition showed a significant change in the latency to dunk (paired $t$-tests: solitary: $t_{17}=-0.8$, $p=0.45$; social: $t_{14}=-1.2, p=0.27$ ), or the total number of dunks (paired $t$-tests: solitary: $t_{17}=-0.3, p=0.78$; social: $t_{14}=-0.1, p=$ $0.89)$. However, birds assigned to the social condition spent significantly less time dunking than they did in their solitary cages (paired $t$-test: $t_{14}=2.8$, $p=0.01$; Figure 5a), whereas birds transferred to the solitary condition showed no change in total dunking time (paired $t$-test: $t_{17}=1.4, p=0.19$; Figure 5a). Further, the longest dunking time was significantly shorter for birds transferred to the social condition (paired $t$-test: $t_{14}=3.1, p=0.007$; Figure $5 \mathrm{~b}$ ), but there was no change for solitary birds (paired $t$-test: $t_{17}=1.3$, $p=0.23$; Figure $5 b)$.

Flexibility in dunking behaviour for birds in social condition

Although birds did not dunk in the hidden water dish, they did adjust their behaviour depending on the placement of the two dishes, which was alternated between trials. During one trial, the open dish was directly beside the 

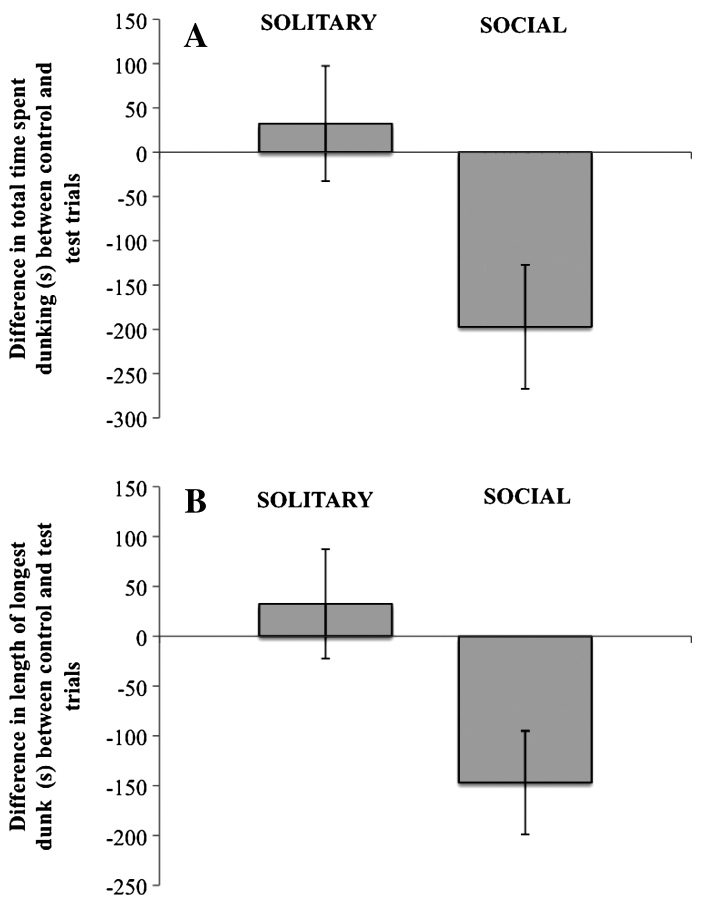

Figure 5. Experiment 3: group means of differences in dunking behaviour between control and test trials in (A) total time spent dunking and (B) length of longest dunk for birds transferred to the solitary $(N=18)$ and social $(N=15)$ conditions. Only birds transferred to the social condition showed a significant difference between control and test trials. Note that means of raw data $\pm \mathrm{SE}$ are shown here; paired $t$-tests were carried out on log-transformed data.

group cage ('near'), whereas in the other trial, the hidden dish was between the open dish and the group cage (making the open dish 'far'). Two of the social treatment birds did not dunk in either trial 3 or trial 4 , though they had dunked in the control trials. We report results only for birds that dunked in at least one of the two trials ( $N=12$, social condition only). We included trial order as a between-subjects variable in our repeated measures ANOVA.

Birds were slower to contact food pellets when the open dish was near to the conspecific cage than when it was far (ANOVA: $F_{1,10}=5.9, p=0.04$ ). They also took longer to dunk their first pellet (ANOVA: $F_{1,10}=10.4, p=$ 0.009 ), dunked for less time (ANOVA: $F_{1,10}=11.0, p=0.008$; Figure 6a), dunked fewer times (ANOVA: $F_{1,10}=10.5, p=0.009$; Figure $6 \mathrm{~b}$ ), and their longest dunk was shorter (ANOVA: $F_{1,10}=5.4, p=0.04$; Figure $6 \mathrm{c}$ ). There was a significant interaction between dish location (near/far) and trial 

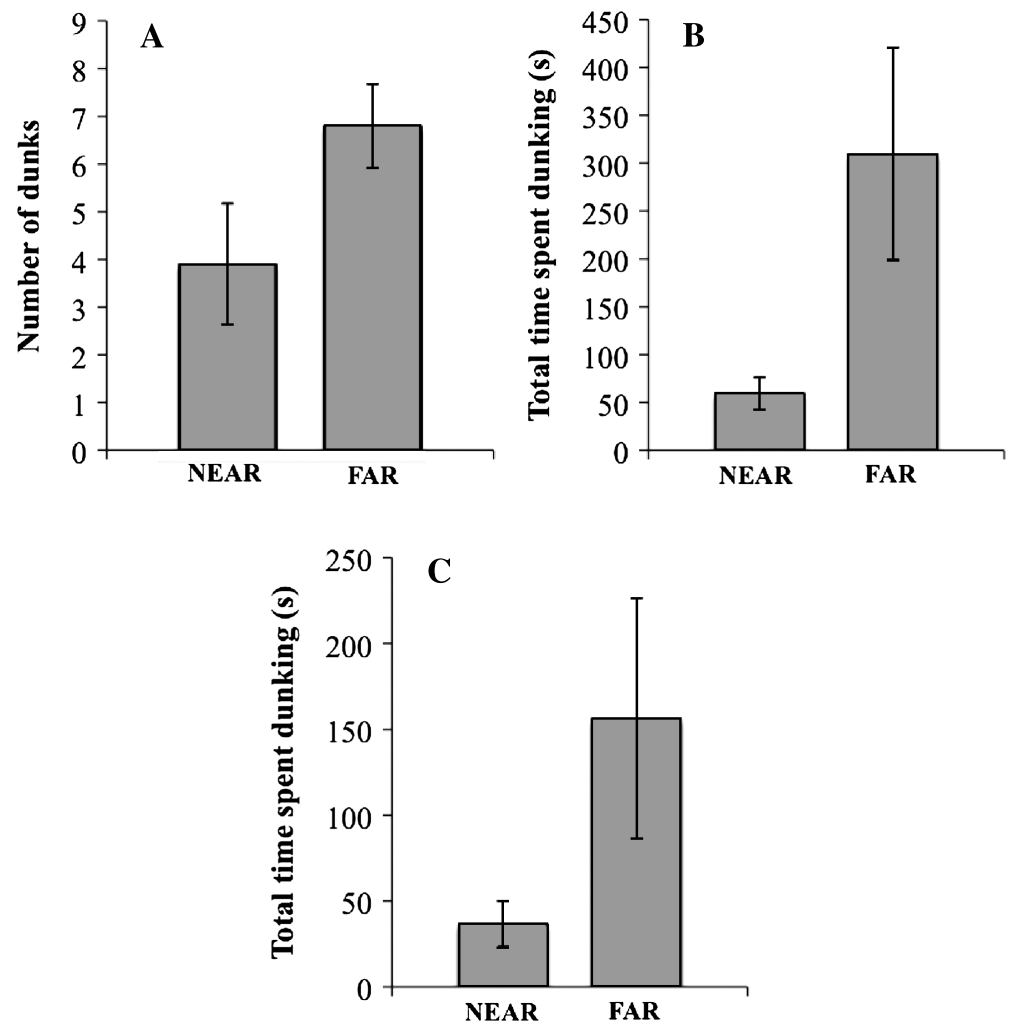

Figure 6. Experiment 3: group means of (A) number of dunks, (B) total time spent dunking and (C) length of longest dunk $\pm \mathrm{SE}$ when focal subjects in the social condition were near to or far from watching conspecifics $(N=12)$. These measures were significantly greater in the far condition. Note that means of raw data $\pm \mathrm{SE}$ are shown here; paired $t$-tests were carried out on log-transformed data.

order for both pellet contact latency and number of dunks (ANOVA: $F_{1,10}=$ $\left.4.8, p=0.05 ; F_{1,10}=14.04, p=0.004\right)$, but the interaction term was not significant for latency to dunk, total time spent dunking, or the longest dunk time (ANOVA: $F_{1,10}=2.3, p=0.17 ; F_{1,10}=1.8, p=0.21 ; F_{1,10}=0.1$, $p=0.74)$.

\section{Discussion}

Our experiments demonstrate that social context influences innovative foraging behaviour in the Carib grackle. We found that lone birds were faster than 
birds observed by conspecifics in attempting novel foraging problems. However, once individuals had contacted a novel problem, there was no difference in how quickly they solved the problem in different social contexts. In addition, whereas social context had no effect on how quickly birds contacted a familiar food (in this case, hard dog food pellets), birds dunked these items less when conspecifics were present, and even less when their preferred water source was closer to other birds. Our results suggest that group-feeding slows down innovation, and reduces the amount of time birds spend using risky foraging techniques such as dunking.

Given that grackles are gregarious birds, it was interesting to find that individuals were hesitant to attempt a problem in the presence of others. There are a number of reasons that this might be the case. It could be that neophobia increases when grackles are in groups, as has been found in common ravens (Stöwe et al., 2006). Novelty responses play an important role in innovation, and neophobia is negatively correlated with innovation both within and among species (Webster \& Lefebvre, 2001; Greenberg, 2003; Boogert et al., 2008). Another possibility is that when individuals are presented with a novel task in the presence of others, it may be useful to wait for social cues. For example, rooks (Corvus frugilegus) copy the food choice of demonstrators when they are presented with novel, but not familiar, foods (Dally et al., 2008). Our group birds were prevented from entering the focal cage by a wire mesh and could not physically approach the innovation tasks. If focal birds perceived this as neophobia on the part of the group birds, or indeed if group birds were acting in a fearful way, this could further prevent them from attempting the innovation task. This effect is consistent with the bystander effect in pigeons, where the presence of uninformed conspecifics near a task reduces the likelihood that a focal individual will learn by observation the solution to a feeding problem (Lefebvre \& Giraldeau, 1994). Carib grackles can learn from each other (Lefebvre et al., 1997a), and will readily scrounge food when given the opportunity (Morand-Ferron et al., 2007). Given the risks associated with novel situations (Bostic, 1966; Tizard, 2004) the best strategy may be to wait for an opportunity to scrounge before trying to solve the problem alone.

It is not surprising that playbacks of an alarm call chorus had a negative effect on the foraging behaviour of individuals (experiment 1). We would expect that birds would direct their attention toward their surroundings instead of solving a novel task when there is a predatory threat as signalled by the 
alarm chorus. What is most interesting is that the simple presence of other birds in an adjacent cage in experiment 2 appears to have had the same effect. This may be because conspecifics represent a source of risk due to competition, and individuals may, thus, avoid contacting the task to avoid conflict (Hoppitt \& Laland, 2008).

The contrast in the results of our experiments may be useful in understanding why foraging behaviour changed between social contexts. The fact that birds were no slower to contact a food source with which they had become familiar throughout the course of the experiments (dog food pellets), but were slower to contact novel tasks in experiments one and two supports the idea that novelty responses play a role in the increased latency to contact problem-solving tasks in our experiment. Once birds had contacted the task in experiments one and two, there was no difference in the speed of innovation in different social contexts. This finding differs from our observations in experiment three, where the presence of other birds reduced the amount of time individuals spent dunking the dog food pellets, particularly when the preferred water source was closer to the group.

For gregarious species, there may be a trade-off between reduced foraging efficiency due to interference, and the presumed benefits of living in a group, such as a dilution of predation risk (Ens \& Goss-Custard, 1984; Moody \& Ruxton, 1996; Grand \& Dill, 1999). In the field, Carib grackles appear to adjust their behaviour depending on the risk of having food items stolen (Morand-Ferron et al., 2006), and the ability to weigh the costs and benefits of their feeding behaviour could explain the differences in results between our experiments. In experiments one and two, birds had no access to food unless they solved the task. Therefore, once they overcame their initial hesitation and began solving the problem, there was no obvious cost to continuing to solve the task as quickly as possible. The fact that they were able to do so suggests that the presence of conspecifics in experiment 2 did not act only as a distraction for test subjects. In experiment 3 , birds had access to highly valuable food items. They contacted the items quickly, but reduced time spent near conspecifics, where theft could occur. Taken together, our experiments demonstrate that Carib grackles are sensitive to the presence of conspecifics, and adjust their feeding behaviour accordingly.

Although dunking reduces handling time and eases ingestion of hard food items (Morand-Ferron et al., 2004, 2006), the presence of others appears to drive individuals to use less risky but less efficient ways of breaking up 
these items. The birds in our experiment were not under any immediate threat of kleptoparasitism, because the social group could not enter the test cage. However, our birds are unlikely to have experienced in the wild a situation in which conspecifics are able to watch and to approach, but not to steal. Thus, our focal birds may have perceived the others as a source of risk. However, we designed our study in a way that eliminated any direct interference and permitted all target subjects an equal opportunity to innovate, allowing an unbiased comparison between isolated subjects and those watched by conspecifics. We can only presume that social effects would have been even stronger had the conspecifics comprising the social group been able to reach the focal bird.

This study confirms the findings of field observations in which wild Carib grackles reduce rates of dunking when foraging group size is larger (MorandFerron et al., 2004, 2006). Our results show that Carib grackles are sensitive to potential risks when they dunk food, much in the same way as western scrub jays (Aphelocoma californica), ravens (Corvus corax) and mountain chickadees (Poecile gambeli) adjust their food caching behaviour when potential pilferers are nearby (Bugnyar \& Kotrschal, 2004; Clayton et al., 2007; Pravosudov, 2008). Although Carib grackles are not closely related to scrub jays, ravens, or chickadees, they share several attributes with these species. They are opportunistic, flexible species, are highly social, and have relatively large brains for their body size (Lefebvre et al., 1997b; Overington, unpublished data). The food-caching paradigm has proven to be an elegant system in which to test hypotheses about the limits of avian cognition (Clayton et al., 2003, 2005; Dally et al., 2006). By expanding these questions to other species and foraging behaviours, we can ask general questions about the role of specific environmental and social pressures in shaping the evolution of cognition (Emery et al., 2007).

If big brains allow animals to innovate and to live in social groups, but social groups repress innovation, a trade-off may emerge between the benefits of finding and eating novel foods and the benefits of feeding in a group. We would predict that animals adjust their behaviour according to these costs and benefits. Group-living can offer anti-predator benefits to individuals, either through warning systems (the 'many eyes' hypothesis) or dilution of risk (Lima \& Dill, 1990). Carib grackles respond quickly to alarm calls of conspecifics, and will join together to mob predators (Griffin \& Galef, 2005). Although benefits of group-feeding have not been quantified for this species, 
it seems likely that being with others affords some protection against predators. Thus, we would predict that when predation risks are lower and theft risks are higher, an individual may forage alone and innovate. On the other hand, when predation risks are high, it may be better to forage with the group and focus less on novel foraging techniques. Thus, the interaction between social foraging pressures, predation risk, and the value of new food items may determine the proportion of innovators found in any given population. An interesting possibility for future studies would be to investigate the effect of conformity on the emergence of innovative feeding behaviour (Day et al., 2001; Whiten et al., 2005). This could be tested on Carib grackles in the field by comparing the range of foraging techniques used by individuals feeding in groups with the same individuals feeding alone.

\section{Acknowledgements}

We thank Kimberly-Ann Côté for her help with the experiments and comments on the manuscript, Andrea S. Griffin for providing us with the alarm calls used in playbacks, and Frank Cézilly, Rémi Wattier and Karine Monceau at the Université de Bourgogne, France for DNA testing of our birds. Comments from Neeltje Boogert and two anonymous referees greatly improved the manuscript. The staff at Bellairs Research Institute provided practical support and encouragement. This work was funded by a Natural Sciences and Engineering Research Council (Canada) Discovery grant to L.L., an NSERC postgraduate scholarship to S.E.O., a Fonds québécois de la recherche sur la nature et les technologies postdoctoral fellowship to J.M.-F., and a travel grant from the Conseil Régional d'Ile de France to L.C.

\section{References}

Biondi, L.M., Bo, M.S. \& Vassallo, A.I. (2008). Experimental assessment of problem solving by Milvago chimango (Aves: Falconiformes). - J. Ethol. 26: 113-118.

Blumstein, D.T., Daniel, J.C. \& Evans, C.S. (2000). Jwatcher 1.0 http://www.jwatcher. ucla.edu/.

Boogert, N.J., Reader, S.M., Hoppitt, W. \& Laland, K.N. (2008). The origin and spread of innovations in starlings. - Anim. Behav. 75: 1509-1518.

Bostic, D.L. (1966). A record of stingray predation by the brown pelican. - Condor 68: 515-516.

Bouchard, J., Goodyer, W. \& Lefebvre, L. (2007). Social learning and innovation are positively correlated in pigeons (Columba livia). — Anim. Cogn. 10: 259-266.

Bugnyar, T. \& Kotrschal, K. (2004). Leading a conspecific away from food in ravens (Corvus corax)? - Anim. Cogn. 7: 69-76.

Byrne, R.W. \& Whiten, A. (1988). Machiavellian intelligence: social expertise and the evolution of intellect in monkeys, apes, and humans. - Oxford University Press, Oxford.

Clayton, N.S. (2004). Is necessity the mother of innovation? — Trends Cogn. Sci. 8: 98-99. 
Clayton, N.S., Bussey, T.J. \& Dickinson, A. (2003). Can animals recall the past and plan for the future? - Nature Rev. Neurosci. 4: 685-691.

Clayton, N.S., Dally, J.M. \& Emery, N.J. (2007). Social cognition by food-caching corvids. The western scrub-jay as a natural psychologist. — Phil. Trans. Roy. Soc. B: Biol. 362: 507-522.

Clayton, N.S., Dally, J., Gilbert, J. \& Dickinson, A. (2005). Food caching by western scrubjays (Aphelocoma californica) is sensitive to the conditions at recovery. - J. Exp. Psychol. Anim. - Behav. Proc. 31: 115-124.

Coleman, S.L. \& Mellgren, R.L. (1994). Neophobia when feeding alone or in flocks in zebra finches, Taenoiopygia guttata. - Anim. Behav. 48: 903-907.

Dally, J.M., Clayton, N.S. \& Emery, N.J. (2008). Social influences on foraging by rooks (Corvus frugilegus). - Behaviour 145: 1101-1124.

Dally, J.M., Emery, N.J. \& Clayton, N.S. (2006). Food-caching western scrub-jays keep track of who was watching when. - Science 312: 1662-1665.

Day, R.L., MacDonald, T., Brown, C., Laland, K.N. \& Reader, S.M. (2001). Interactions between shoal size and conformity in guppy social foraging. - Anim. Behav. 62: 917925.

Dunbar, R.I.M. (1998). The social brain hypothesis. — Evol. Anthropol. 6: 178-190.

Emery, N.J., Seed, A.M., von Bayern, A.M.P. \& Clayton, N.S. (2007). Cognitive adaptations of social bonding in birds. - Phil. Trans. Roy. Soc. B: Biol. 362: 489-505.

Ens, B.J. \& Goss-Custard, J.D. (1984). Interference among oystercatchers, Haematopus ostralegus, feeding on mussels, Mytilus edulis, on the Exe estuary. - J. Anim. Ecol. 53: 217-231.

Fragaszy, D.M. \& Visalberghi, E. (1990). Social processes affecting the appearance of innovative behaviours in capuchin monkeys. - Folia Primatol. 54: 155-165.

Gayou, D.C. (1982). Tool use by green jays. — Wilson Bull. 94: 593-594.

Grand, T.C. \& Dill, L.M. (1999). The effect of group size on the foraging behaviour of juvenile coho salmon: reduction of predation risk or increased competition? - Anim. Behav. 58: 443-451.

Greenberg, R. (2003). The role of neophobia and neophilia in the development of innovative behaviour of birds. - In: Animal innovation (Reader, S.M. \& Laland, K.N., eds). Oxford University Press, Oxford, p. 175-196.

Griffin, A.S. \& Galef, B.G. (2005). Social learning about predators: does timing matter? Anim. Behav. 69: 669-678.

Griffin, A.S., Savani, R.S., Hausmanis, K. \& Lefebvre, L. (2005). Mixed-species aggregations in birds: zenaida doves, Zenaida aurita, respond to the alarm calls of carib grackles, Quiscalus lugubris. - Anim. Behav. 70: 507-515.

Griffiths, R., Double, M.C., Orr, K. \& Dawson, R.J.G. (1998). A DNA test to sex most birds. - Mol. Ecol. 7: 1071-1075.

Hoppitt, W. \& Laland, K.N. (2008). Social processes affecting feeding and drinking in the domestic fowl. - Anim. Behav. 76: 1529-1543.

Huber, L. \& Gajdon, G.K. (2006). Technical intelligence in animals: the kea model. — Anim. Cogn. 9: 295-305.

Jaramillo, A. \& Burke, P. (1999). New World Blackbirds: The Icterids. — Christopher Helm, London.

Lefebvre, L. \& Bouchard, J. (2003). Social learning about food in birds. — In: The biology of traditions: models and evidence (Fragaszy, D.M. \& Perry, S., eds). Cambridge University Press, Cambridge, p. 94-126. 
Lefebvre, L. \& Giraldeau, L.A. (1994). Cultural transmission in pigeons is affected by the number of tutors and bystanders present. - Anim. Behav. 47: 331-337.

Lefebvre, L., Templeton, J.J., Brown, K. \& Koelle, M. (1997a). Carib grackles imitate conspecific and Zenaida dove tutors. - Behaviour 134: 1003-1017.

Lefebvre, L., Whittle, P., Lascaris, E. \& Finkelstein, A. (1997b). Feeding innovations and forebrain size in birds. - Anim. Behav. 53: 549-560.

Lima, S.L. \& Dill, L.M. (1990). Behavioural decisions made under the risk of predation: a review and prospectus. - Can. J. Zool. 68: 619-640.

Moody, A.L. \& Ruxton, G.D. (1996). The intensity of interference varies with food density: support for behaviour-based models of interference. - Oecologia 108: 446-449.

Morand-Ferron, J., Giraldeau, L.A. \& Lefebvre, L. (2007). Wild Carib grackles play a producer-scrounger game. - Behav. Ecol. 18: 916-921.

Morand-Ferron, J., Lefebvre, L., Reader, S.M., Sol, D. \& Elvin, S. (2004). Dunking behaviour in Carib grackles. - Anim. Behav. 68: 1267-1274.

Morand-Ferron, J., Veillette, M. \& Lefebvre, L. (2006). Stealing of dunked food in Carib grackles (Quiscalus lugubris). — Behav. Proc. 73: 342-347.

Nicolakakis, N., Sol, D. \& Lefebvre, L. (2003). Behavioural flexibility predicts species richness in birds, but not extinction risk. - Anim. Behav. 65: 445-452.

Overington, S.E., Dubois, F. \& Lefebvre, L. (2008). Food unpredictability drives both generalism and social foraging: a game theoretical model. — Behav. Ecol. 19: 836-841.

Pravosudov, V.V. (2008). Mountain chickadees discriminate between potential cache pilferers and non-pilferers. — Proc. Roy. Soc. Lond. B: Biol. 275: 55-61.

Reader, S.M. \& Laland, K.N. (2000). Diffusion of foraging innovations in the guppy. Anim. Behav. 60: 175-180.

Reader, S.M. \& Laland, K.N. (2002). Social intelligence, innovation, and enhanced brain size in primates. - Proc. Natl. Acad. Sci. USA 99: 4436-4441.

Reader, S.M. \& Laland, K.N. (2003). Animal innovation. — Oxford University Press, Oxford.

Shultz, S. \& Dunbar, R.I.M. (2006). Both social and ecological factors predict ungulate brain size. - Proc. Roy. Soc. Lond. B: Biol. 273: 207-215.

Sibson, R.B. (1993). Bellbirds eating fruits of strawberry trees. — Notornis 40: 177.

Sol, D., Stirling, D.G. \& Lefebvre, L. (2005). Behavioural drive or behavioural inhibition in evolution: Subspecific diversification in holarctic passerines. — Evolution 59: 26692677.

Stöwe, M., Bugnyar, T., Heinrich, B. \& Kotrschal, K. (2006). Effects of group size on approach to novel objects in ravens (Corvus corax). — Ethology 112: 1079-1088.

Tizard, I. (2004). Salmonellosis in wild birds. — Semin. Avian Exotic Pet Med. 13: 50-66.

Webster, S.J. \& Lefebvre, L. (2001). Problem solving and neophobia in a columbiformpasseriform assemblage in Barbados. - Anim. Behav. 62: 23-32.

Whiten, A., Horner, V. \& de Waal, F.B.M. (2005). Conformity to cultural norms of tool use in chimpanzees. - Nature 437: 737-740. 